\title{
The LiaFSR and BsrXRS Systems Contribute to Bile Salt Resistance in Enterococcus faecium Isolates
}

\author{
Luoxiong Zhou ${ }^{1}$, Lihong Wang ${ }^{1}$, Ping Tian', Tingting Bao ${ }^{1}$, Lianbin $\mathrm{Li}^{1}$ and Xin Zhao ${ }^{1,2 *}$ \\ ${ }^{1}$ College of Animal Science and Technology, Northwest A\&F University, Xianyang, China, ${ }^{2}$ Department of Animal Science, \\ McGill University, Montreal, QC, Canada
}

Two-component systems (TCSs) are dominant regulating components in bacteria for responding to environmental stimuli. However, little information is available on how TCSs in Enterococcus faecium respond to bile salts - an important environmental stimulus for intestinal bacteria. In this study, the gene expression of 2 TCSs, BsrXRS and LiaFSR, was positively correlated with survival rates of different $E$. faecium isolates during exposure to ox gall. Moreover, gene disruptions of bsrR, bsrS, liaS, and liaR significantly reduced the survival rates of $E$. faecium in the presence of ox gall. Finally,

OPEN ACCESS

Edited by:

Marie-Joelle Virolle,

Centre National de la Recherche

Scientifique (CNRS), France

Reviewed by:

Jean-Christophe Giard,

University of Caen Normandy, France

Cécile Muller,

University of Caen Normandy, France

${ }^{*}$ Correspondence:

Xin Zhao

xin.zhao@mcgill.ca

Specialty section:

This article was submitted to

Microbial Physiology and Metabolism,

a section of the journal

Frontiers in Microbiology

Received: 15 January 2019

Accepted: 25 April 2019

Published: 10 May 2019

Citation:

Zhou L, Wang L, Tian P, Bao T,

Li L and Zhao X (2019) The LiaFSR and BsrXRS Systems Contribute

to Bile Salt Resistance

in Enterococcus faecium Isolates.

Front. Microbiol. 10:1048.

doi: 10.3389/fmicb.2019.01048
EMSA results indicated that BsrR functioned as a transcription regulator for expression of its own gene as well as lipoate-protein ligase A (Ip/A). Additional 27 potential target genes by BsrR were revealed through in silico analyses. These findings suggest that BsrXRS and LiaFSR systems play important roles in bile salt resistance in E. faecium.

Keywords: two-component systems, Enterococcus faecium, bile salts, LiaFSR, BsrXRS

\section{INTRODUCTION}

Bile salts are known as a natural detergent that emulsifies and solubilizes lipids, thereby playing a crucial role in fat digestion and absorption. At the same time, the amphipathic property of bile salts may induce membrane damage and impair membrane functions of intestinal bacteria. In addition to attacking cell membrane, bile salts have numerous other toxic effects on bacterial cells including disturbing macromolecule stability and inducing oxidative stress, DNA damage and protein misfolding in bacterial cells (Ruiz et al., 2013). Thus, the ability to adapt and respond to bile salts is essential for the survival and persistence of intestinal bacteria in gastrointestinal tracts.

Two-component systems (TCSs) are a primary means by which bacteria sense and respond to their environmental changes (Capra and Laub, 2012; Groisman, 2016). Although exact mechanisms for bacteria to respond to bile salts have not been completely elucidated, it is likely to be associated with TCSs. A typical TCS consists of two proteins: a signal-sensing histidine protein kinase (HK) in the cell membrane that senses an environmental change, and a cytoplasmic cognate response regulator (RR) that generates an appropriate response, usually regulating expression of target genes.

Several studies have shown that several types of bacteria can up-regulate expression of TCS genes and proteins in the presence of bile salts. For example, exposure to bile salts significantly increased expression of baeS-baeR, phoP3-phoR3, and vraR-vraS in Lactobacillus rhamnosus GG (Koskenniemi et al., 2011). A whole-genome microarray analysis of Lactobacillus acidophilus NCFM found a significant up-regulation of a TCS operon (LBA1425 to LBA1432) in response to bile salts and mutations in the HK (LBA1430) and the RR (LBA1431) of this operon decreased 
the survival rates (Pfeiler et al., 2007). Similarly, basR and basS genes were up-regulated after exposure to bile salts in Escherichia coli O157:H7 (Kus et al., 2011). E. coli Nissle 1917 became more resistant to bile salts after introduction of a mutated envZ (env $\left.Z_{\mathrm{P} 41 \mathrm{~L}}\right)$ from E. coli MG1655 (the env $Z$ gene encodes a histidine kinase and induces a higher level of phosphorylated OmpR) (Adediran et al., 2014). In Propionibacterium freudenreichii SI41, addition of bile salts was found to induce expression of a putative RR (ORF0001) protein at two-dimensional electrophoresis (Leverrier et al., 2003). In another study, a RR (BL1000) was detected when exposure to ox bile in Bifidobacterium longum NCIMB 8809 (Sanchez et al., 2005). Disruption of cbrR in Campylobacter jejuni F38011 rendered the strain more sensitive to ox bile (Raphael et al., 2005). Mutation of the cpxAR in Klebsiella pneumoniae NTUH-K2044 led to low survival rates during exposure to bile at the concentrations higher than $0.5 \%$ (Srinivasan et al., 2012). Le Breton et al. (2003) found that mRNA amount of ehk10err 10 was increased after incubation with $0.08 \%$ bile salts in Enterococcus faecalis $\mathrm{JH} 2-2$. However, the expression of ehk10err 10 TCS was not significantly increased in a transcriptional analysis of E. faecalis V583 response to ox gall (Solheim et al., 2007). Collectively, these findings suggest that TCSs are essential for resistance to bile salts in various bacterial species. However, there is no information available on involvement of TCSs in the bile resistance in E. faecium.

Enterococcus faecium is a common commensal organism in the gastrointestinal tract of a wide variety of hosts. At the same time, it is also an important cause of multidrug-resistant hospitalacquired infection (Lebreton et al., 2013). Moreover, E. faecium strains have been considered as potential bio-preservatives due to the strong antimicrobial activity against Listeria monocytogenes in fermented food production (Pingitore et al., 2012; Favaro et al., 2014). As an important group of lactic acid bacteria (LAB), E. faecium has been used as probiotics to confer health benefit to the host (Veljovic et al., 2017). E. faecium harbors more than 15 TCSs in the chromosome and in plasmids (Ortet et al., 2015). Four TCSs in E. faecium, CroRS, ChtRS, LiaFSR, and VanSR, have been characterized for antibiotic resistance. The CroRS system responds to cell wall stress and is critical for the resistance against cell wall-targeting antibiotics in E. faecium. Mutation of croRS in the E. faecium 1,141,733 strain remarkably reduced the resistance to cefepime and ceftriaxone (Kellogg et al., 2017). Guzman Prieto et al. (2017) revealed that the ChtRS system contributed to chlorhexidine tolerance. Mutants of chtR and chtS exhibited a slower exponential growth rate than the wild-type E. faecium E1162 in the presence of chlorhexidine. The LiaFSR system is an important regulator of the cell envelope stress response to the membrane-targeting agents (Tran et al., 2016). This system consists of a sensor histidine kinase (LiaS), a response regulator (LiaR) and a membrane-anchored protein (LiaF) that negatively affect the function of LiaS. The role of LiaFSR in enterococci has been described recently in resistance to daptomycin (Tran et al., 2016). Deletion of liaR in E. faecium $\mathrm{R} 446 \mathrm{~F}$ and R497 that resistant to daptomycin fully reversed resistance (Panesso et al., 2015). The VanSR two-component system regulates the downstream van gene cluster, which alters the cell wall precursors to allow bacteria to resist vancomycin (Hong et al., 2008).

The objective of this study was to identify potential TCSs in the resistance of E. faecium to bile salts. Our results show that the gene expression of liaS, liaR, $b s r R$, and $b s r S$ was positively correlated with survival rate of different E. faecium isolates after exposure to bile salts. Moreover, gene disruptions of $b s r R$, $b s r S$, lias, and liaR significantly reduced the survival rates of E. faecium after exposure to different concentrations of bile salts. In addition, BsrR could function as a transcription regulator for its own expression and expression of $l p l A$. The in silico analyses also revealed 27 other target genes for BsrR. These findings provide a first glance at the molecular mechanisms for bile salt resistance in E. faecium.

\section{MATERIALS AND METHODS}

\section{Bacterial Strains, Plasmids, and Culture Conditions}

Enterococcus faecium isolates, E. coli strains and plasmids used in this study are listed in Table 1. E. faecium were isolated from a previous study (Feng et al., 2016). E. faecium isolates were identified by $16 \mathrm{~s}$ rRNA gene sequencing and subsequent blasting of the sequences, using the Basic Local Alignment Search Tool (BLAST) program. The genomic DNA was extracted from overnight culture using an EasyPure Genomic DNA kit (TransGen Biotech, Beijing, China) as per manufacturer's protocol. A PCR reaction was performed to amplify the $16 \mathrm{~S}$ rRNA genes using universal primers 27F and 1492R (Supplementary Table S1). PCR products were then sequenced using the Sanger sequencing. E. faecium isolates were routinely grown in the de Man, Rogosa, and Sharpe (MRS) broth or on the agar at $37^{\circ}$ C. E. coli EC1000 (Leenhouts, 1996) was used for plasmid construction and was grown in the Luria-Bertani (LB) broth at $30^{\circ} \mathrm{C}$. Where necessary, antibiotics were used at the following concentrations: chloramphenicol $5 \mu \mathrm{g} / \mathrm{ml}$ for E. faecium, spectinomycin $300 \mu \mathrm{g} / \mathrm{ml}$ for E. faecium, and $100 \mu \mathrm{g} / \mathrm{ml}$ for E. coli, ampicillin $100 \mu \mathrm{g} / \mathrm{ml}$ for $E$. coli. All antibiotics were obtained from Sigma (St. Louis, MO, United States).

\section{Resistance of E. faecium to Bile Salts}

To determine the resistant abilities of $8 \mathrm{E}$. faecium isolates to bile salts, overnight cultures were diluted 100 -fold in $20 \mathrm{ml}$ of the fresh MSR medium. When bacterial cells were grown to the mid-log-phase $\left(\mathrm{OD}_{600}\right.$ of $\left.\sim 0.4\right), 1 \mathrm{ml}$ aliquots of the cultures were collected as control samples $(t=0 \mathrm{~min})$. Another $1 \mathrm{ml}$ aliquots of the cultures were collected and centrifuged at $12,000 \times g$ for $2 \mathrm{~min}$, then re-suspended in the same volume of the fresh medium supplemented with different concentrations of $0.5,1,2$, and $5 \%$ bile salts (Ox gall, Sigma, United States). After incubation for $30 \mathrm{~min}$ at $37^{\circ} \mathrm{C}(t=30 \mathrm{~min})$, the numbers of colony-forming units per milliliter $(\mathrm{CFU} / \mathrm{ml})$ of each sample were determined by plating a serial of 10 -fold dilutions on MRS agar and then incubated at $37^{\circ} \mathrm{C}$ for $48 \mathrm{~h}$. The percentage survival of E. faecium in bile salts was calculated by comparing CFU at 
TABLE 1 | Strains and plasmids used in this study.

\begin{tabular}{|c|c|c|}
\hline $\begin{array}{l}\text { Strain or } \\
\text { plasmid }\end{array}$ & Description ${ }^{b}$ & References \\
\hline \multicolumn{3}{|l|}{ Strains } \\
\hline \multicolumn{3}{|l|}{ E. faecium ${ }^{\mathrm{a}}$} \\
\hline NW1 & Isolated from duodenum & Feng et al., 2016 \\
\hline NW2 & Isolated from duodenum & Feng et al., 2016 \\
\hline NW3 & Isolated from duodenum & Feng et al., 2016 \\
\hline NW4 & Isolated from cecum & Feng et al., 2016 \\
\hline NW5 & Isolated from muscular stomach & Feng et al., 2016 \\
\hline NW6 & Isolated from cecum & Feng et al., 2016 \\
\hline NW7 & Isolated from muscular stomach & Feng et al., 2016 \\
\hline NW8 & Isolated from jejunum & Feng et al., 2016 \\
\hline liaR::pWS3 & $\begin{array}{l}\text { Single-crossover insertional mutant of } \\
\text { liaR of NW2 }\end{array}$ & This study \\
\hline liaS::pWS3 & $\begin{array}{l}\text { Single-crossover insertional mutant of } \\
\text { liaS of NW2 }\end{array}$ & This study \\
\hline bsrR::pWS3 & $\begin{array}{l}\text { Single-crossover insertional mutant of } \\
b s r R \text { of NW2 }\end{array}$ & This study \\
\hline bsrS::pWS3 & $\begin{array}{l}\text { Single-crossover insertional mutant of } \\
\text { bsrS of NW2 }\end{array}$ & This study \\
\hline liaS::pWS3+liaS & $\begin{array}{l}\text { Complementation strain of liaS::pWS3; } \\
\text { liaS::pWS3 harboring pRB473-liaS }\end{array}$ & This study \\
\hline \multicolumn{3}{|l|}{ E. coli } \\
\hline EC1000 & Host strain for pWS3 derived vectors & Leenhouts, 1996 \\
\hline $\mathrm{DH} 5 \alpha$ & Host strain for routine cloning & Lab stock \\
\hline BL21 (DE3) & E. coli overexpression host & Lab stock \\
\hline \multicolumn{3}{|l|}{ Plasmids } \\
\hline pWS3 & $\begin{array}{l}\text { Gram-positive thermosensitive plasmid } \\
\text { for gene disruption, Spec }{ }^{r}\end{array}$ & $\begin{array}{l}\text { Zhang et al., } \\
2011\end{array}$ \\
\hline pWS3-LiaR & $\begin{array}{l}\text { pWS3 containing a 489-bp Kpnl/EcoRl } \\
\text { internal fragment of liaR gene }\end{array}$ & This study \\
\hline pWS3-LiaS & $\begin{array}{l}\text { pWS3 containing a } 827-b p \text { Kpnl/EcoRl } \\
\text { internal fragment of liaS gene }\end{array}$ & This Study \\
\hline pWS3-BsrR & $\begin{array}{l}\text { pWS3 containing a 505-bp Kpnl/EcoRl } \\
\text { internal fragment of bsrR gene }\end{array}$ & This Study \\
\hline pWS3-BsrS & $\begin{array}{l}\text { pWS3 containing a 1,015-bp Kpnl/Xhol } \\
\text { internal fragment of bsrS gene }\end{array}$ & This Study \\
\hline pRB473 & Broad-range shuttle vector, $\mathrm{Amp}^{r}, \mathrm{Cm}^{r}$ & $\begin{array}{l}\text { Brückner et al., } \\
1993\end{array}$ \\
\hline pRB473-liaS & $\begin{array}{l}\text { Complementation plasmid for liaS, } \\
\text { pRB473 carrying gene liaS }\end{array}$ & This Study \\
\hline pET21b (+) & The expression plasmid, Amp ${ }^{r}$ & Lab stock \\
\hline pET21b-BsrR & The expression plasmid for BsrR protein & This Study \\
\hline
\end{tabular}

${ }^{a}$ All E. faecium isolates were isolated from the chicken gastrointestinal tract. ' ${ }^{b}$ Specr, spectinomycin resistance; $\mathrm{Amp}^{r}$, Ampicillin resistance; $\mathrm{Cm}^{r}$, chloramphenicol resistance.

$30 \mathrm{~min}$ to CFU at time zero. The assays were performed in three independent experiments.

\section{RNA Preparation, RT-PCR, and RT-qPCR}

Eight TCSs in E. faecium genomes were selected to study the effect of TCSs on resistance to bile salts. Among them, 5 TCSs are homologous to TCSs in other species known to be involved in bile resistance (Supplementary Table S2), while ChtRS, CroRS, and LiaFSR were selected because they respond to cell envelope-targeting antimicrobial agents. To quantify gene expression, overnight cultures were diluted 100-fold in $20 \mathrm{ml}$ of the fresh MSR medium. When bacterial cells were grown to the mid-log-phase $\left(\mathrm{OD}_{600}\right.$ of $\left.\sim 0.4\right), 5 \mathrm{ml}$ aliquots of the culture were centrifuged for $2 \mathrm{~min}$ at $12,000 \times g$ at $4^{\circ} \mathrm{C}$ and pellets were flash frozen in liquid N2 prior to RNA extraction. This sample served as the control $(t=0 \mathrm{~min})$ prior to the addition of bile salts. Bile salts (final concentration $0.5 \%$, w/v) were added into the remaining culture. After $30 \mathrm{~min}$ of incubation at $37^{\circ} \mathrm{C}, 5 \mathrm{ml}$ aliquots of the culture were centrifuged and flash frozen as described above. Total RNA was extracted by using the E.Z.N.A. Bacterial RNA Kit (Omega, United States). One $\mu \mathrm{g}$ of extracted RNA was converted into cDNA using a PrimeScript ${ }^{\mathrm{TM}}$ RT reagent Kit (Takara, Dalian, China) according to the manufacturer's instructions. To identify the transcript structure, reverse transcription-PCR (RT-PCR) was performed on cDNA synthesized from wild-type E. faecium NW2 RNA with primers listed in Supplementary Table S1. RNA without RT and genomic DNA were used as the negative control and positive control, respectively. The levels of expression of genes were determined by quantitative real-time RT-PCR (RT-qPCR) using a real-time PCR kit (Takara, Dalian, China) and specific primers (Supplementary Table S1). The transcript levels were determined by the $2^{-\Delta \Delta C t}$ method using the adk gene as an endogenous control gene.

\section{Generation of Insertional Mutants and in trans Complementation}

To verify whether the LiaFSR and BsrXRS systems were responsible for resistance to bile salts, gene disruption mutants were constructed in E. faecium NW2 as previously described Zhang et al. (2011). The internal DNA fragments of liaR, liaS, bsrR, and bsrS genes were amplified using primers LiaR-mut-F/LiaR-mut-R, LiaS-mut-F/LiaS-mut-R, BsrR-mutF/BsrR-mut-R, and BsrS-mut-F/BsrS-mut-R, respectively (Supplementary Table S1), and cloned to a Gram-positive thermosensitive vector pWS3. The resulting constructs were transformed into E. coli EC1000 for propagation and grown on $\mathrm{LB}$ plates containing $100 \mu \mathrm{g} / \mathrm{ml}$ spectinomycin at $30^{\circ} \mathrm{C}$. The inserts from each construct were sequenced using the primers M13-F and SK-R to ensure that no mutations arose during cloning. The correct vectors (Table 1) were then electrotransformed into E. faecium NW2 using Gene Pulser Xcell $^{\mathrm{TM}}$ apparatus (Bio-Rad), operating at 2,500 V, $25 \mathrm{mF}$ capacitance, $200 \Omega$ resistance, and 2 - $\mathrm{mm}$ cuvettes that contained $2 \mu \mathrm{g}$ of plasmid DNA plus $100 \mu \mathrm{l}$ of electrocompetent cells. The electrocompetent cells were obtained as previously described (Zhang et al., 2012). After electrotransformation, the cells were allowed to recover for $2 \mathrm{~h}$ at the permissive temperature of $30^{\circ} \mathrm{C}$, after which the cells were plated on $\mathrm{BHI}$ plates supplemented with $300 \mu \mathrm{g} / \mathrm{ml}$ spectinomycin at $30^{\circ} \mathrm{C}$ to select for transformants. Spectinomycin-resistant colonies were picked and grown overnight in $2 \mathrm{ml}$ of $\mathrm{BHI}$ broth supplemented with $300 \mu \mathrm{g} / \mathrm{ml}$ spectinomycin at an elevated temperature $\left(37^{\circ} \mathrm{C}\right)$ to cure the plasmid. Following serial passages at $37^{\circ} \mathrm{C}$, the cells were then plated on BHI agar plates with $300 \mu \mathrm{g} / \mathrm{ml}$ spectinomycin at $37^{\circ} \mathrm{C}$. Single-cross-over integration into liaR, liaS, bsrR, or 
bsrS was verified by PCR with pWS3-specific primer SK-R and gene-specific primers LiaR-d-check, LiaS-d-check, BsrR-d-check, BsrS-d-check, respectively (Supplementary Table S1).

The liaS mutant was complemented in trans by cloning liaS gene into the shuttle plasmid pRB473 (Brückner et al., 1993). The gene lias fragment was generated from the NW2 genomic DNA using primers LiaS-comp-F and LiaS-comp-R (Supplementary Table S1). The PCR product was then ligated into pRB473, generating the complementation plasmid pRB473liaS. Sequencing of the full insert was performed to verify the absence of errors. The correct plasmid was introduced into the liaS mutant strain by electroporation as described above. Unfortunately, despite repeated attempts, we were unable to obtain complemented strains for liaR, bsrR, and $b s r S$ genes.

\section{Search of the Binding Sites and Target Genes of BsrR in E. faecium in silico}

Available complete genome sequence of the E. faecium DO was downloaded from the NCBI RefSeq database in GenBank (.gbk) format. The amino acid sequence of BsrR orthologs from 7 bacterial species (including E. faecium DO) in the Enterococcus genus were downloaded from OrtholugeDB (Whiteside et al., 2013). The upstream DNA sequences of BsrXRS system from 7 bacterial species were obtained from the NCBI GenBank database. Then these DNA sequences were used to search the putative binding sites for BsrR using the motif finding in DMINDA 2.0 web server with default parameters (Yang et al., 2017). As for searching target genes, all promoter sequences in the E. faecium DO genome were downloaded from DOOR 2.0 (Mao et al., 2014) and submitted to DMINDA 2.0. Multiple sequence alignments of DNA and protein sequences were performed using the CLUSTAL W (Thompson et al., 1994).

\section{Overexpression and Purification of BsrR}

To further examine if the predicted binding sites are directly bound by BsrR, we used the electrophoretic mobility shift assays (EMSAs) to detect the protein-DNA interactions. The $b s r R$ gene was amplified from the NW2 genome using primers BsrRc-F/BsrRc-R and cloned into the pET21b vector, then was transformed into E. coli strain BL21 (DE3) for overexpressing C-terminally six-His-tagged BsrR. Successful transformants were inoculated into LB broth containing ampicillin $(100 \mu \mathrm{g} / \mathrm{ml})$ and incubated at $37^{\circ} \mathrm{C}$ with vigorous shaking $(200 \mathrm{rpm})$ to achieve an $\mathrm{OD}_{600}$ of 0.55 . Once the correct $\mathrm{OD}_{600}$ obtained, cultures were kept on ice for $10 \mathrm{~min}$ followed by the addition of $0.1 \mathrm{mM}$ (final concentration) isopropyl- $\beta$-D-1-thiogalactopyranoside (IPTG) to induce BsrR expression. The cultures were further incubated at $18^{\circ} \mathrm{C}$ for overnight, and the cells were harvested by centrifugation at $12,000 \times g$ for $5 \mathrm{~min}$ at $4^{\circ} \mathrm{C}$. To purify the recombinant $\mathrm{BsrR}$, the cell pellet was resuspended in binding buffer [ $15 \mathrm{mM}$ imidazole, $50 \mathrm{mM}$ Tris- $\mathrm{HCl}, 0.5 \mathrm{mM}$ EDTA, $50 \mathrm{mM} \mathrm{NaCl}$ and $10 \%$ glycerol $(\mathrm{v} / \mathrm{v}), \mathrm{pH}=7.5$ ] and disrupted by sonication, and the cell debris was removed by centrifugation at $12,000 \times g$ for $15 \mathrm{~min}$ at $4^{\circ} \mathrm{C}$. This soluble fraction, which contained the BsrR protein, was placed in a HisTrap prepacked column (GE healthcare). The same binding buffer was used for equilibration of the column. Whole-cell lysate was allowed to bind to the resin. The column was then washed five times with binding buffer. Bound BsrR were eluted using elution buffer containing $250 \mathrm{mM}$ imidazole $[250 \mathrm{mM}$ imidazole, $50 \mathrm{mM}$ Tris$\mathrm{HCl}, 0.5 \mathrm{mM}$ EDTA, $50 \mathrm{mM} \mathrm{NaCl}, 10 \%$ glycerol (v/v), $\mathrm{pH}=7.5$ ]. The eluted samples were dialyzed in the storage buffer $[10 \mathrm{mM}$ Tris, $50 \mathrm{mM} \mathrm{KCl,} 1 \mathrm{mM}$ DTT, $10 \%$ glycerol (v/v), pH 7.5] at $4^{\circ} \mathrm{C}$. The concentration of BsrR protein was determined by the Bradford assay (Bio-Rad) using the bovine serum albumin (BSA) as the standard.

\section{Electrophoretic Mobility Shift Assays (EMSAs)}

The intergenic regions upstream of $b s r X(143 \mathrm{bp})$ and $l p l A$ (162 bp) were amplified from the E. faecium NW2 genomic DNA using the primers $\mathrm{pBsrRS}-\mathrm{F} / \mathrm{pBsrRS}-\mathrm{R}$ and pLplA-F/pLplA-R (Supplementary Table S1), respectively. A DNA fragment as a negative control was amplified from the coding region of housekeeping gene $d d l \mathrm{~A}$ using the primer $\mathrm{pNC}-\mathrm{F} / \mathrm{pNC}-\mathrm{R}$, which does not share sequence identity with the upstream of $b s r X$ and $l p l A$. The EMSA experiments were performed using the LightShift EMSA Optimization and Control Kit according to the manufacturer's instructions (Pierce, Thermo Fisher Scientific, Waltham, MA, United States). Briefly, the $5^{\prime}$-end biotin labeled DNA probes $(20 \mathrm{fmol})$ were incubated with various concentrations of recombinant BsrR protein $(0,0.1,0.2$, and $0.3 \mathrm{nM})$ in binding reaction $(20 \mu \mathrm{l})$ containing $10 \mathrm{mM}$ Tris- $\mathrm{HCl}$ (pH 7.5), $50 \mathrm{mM} \mathrm{KCl}, 0.5 \mathrm{mM}$ DTT, $1 \mathrm{mM}$ EDTA, 7.5\% glycerol, $1 \mathrm{mg}$ of BSA per ml, and $1 \mu \mathrm{g}$ of poly (dI-dC). To verify the specificity of BsrR-probe interaction, 200-fold excess amounts of unlabeled non-specific DNA (negative control) or each unlabeled specific probe were first incubated with BsrR protein for $20 \mathrm{~min}$, followed by the addition of each labeled specific probe. Reactions were incubated for $40 \mathrm{~min}$ at $25^{\circ} \mathrm{C}$, and then were loaded in $6 \%$ non-denaturing polyacrylamide gels containing $5 \%$ glycerol and electrophoresed in the $0.5 \times$ Tris-borate-EDTA (TBE) for $90 \mathrm{~min}$ at $120 \mathrm{~V}$ and $4^{\circ} \mathrm{C}$. Biotin-labeled DNA-protein complexes were detected using the Chemiluminescent Nucleic Acid Detection Module Kit follow according to the manufacturer's instructions (Pierce, Thermo Fisher Scientific).

\section{Statistical Analysis}

One-way analysis of variance (ANOVA) was used to analyze data using the $\mathrm{R}$ software (Version 3.4.3) (R Core Team, 2017). The differences between treatment means were calculated using the Duncan's new multiple range test in the Agricolae Packages (Version 1.2-8) (Mendiburu, 2017). Data are expressed as mean \pm standard deviation (SD) and $P<0.05$ was considered significantly different.

\section{RESULTS}

\section{Resistance of E. faecium to Ox Gall}

To assay the resistant abilities to ox gall of 8 E. faecium isolates, the survival rates were measured in the MRS broth supplemented 

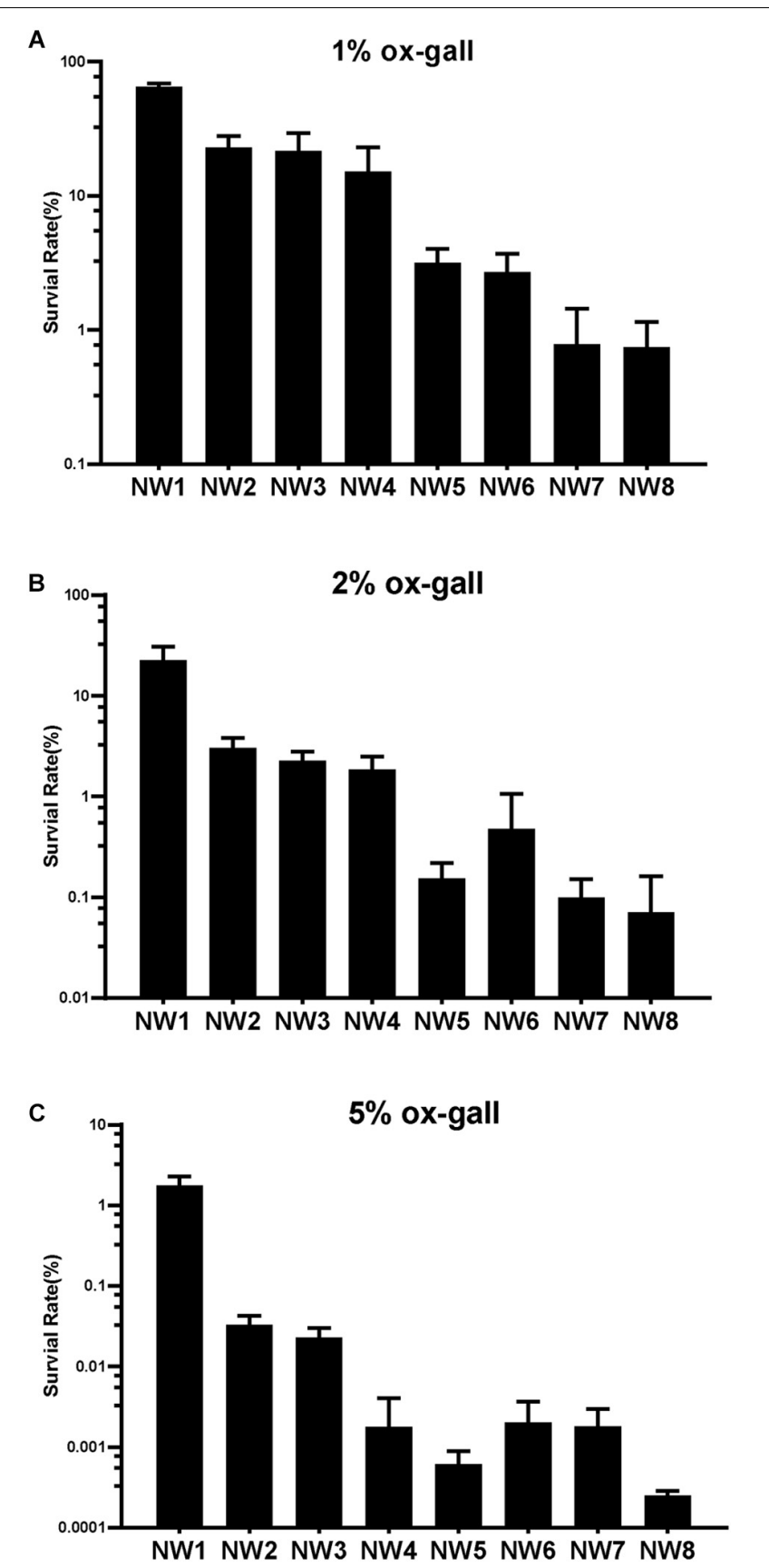

FIGURE 1 | Resistance of Enterococcus faecium to bile salts. Survival rates of E. faecium isolates after 30 min exposure to 1 (A), 2 (B), and $5 \%$ (C) ox gall. Data are shown as mean \pm SD from three independent biological replicates.

with different concentrations of ox gall. The resistant activities to bile salts varied widely among the isolates. After exposure to $1 \%$ ox gall, more than $20 \%$ of E. faecium NW1, 2, and 3 remained viable, whereas the survival rate of NW7 and 8 fell below 1\% (Figure 1A). After exposure to $2 \%$ ox gall, E. faecium NW1, 2, 3 still had more than $1 \%$ survival rates, whereas survival rates of E. faecium NW7 and 8 were lower than $0.1 \%$ (Figure 1B). When the concentration of ox gall was increased to $5 \%$, the survival of all
E. faecium isolates except NW1 was less than $0.1 \%$ (Figure 1C). On the other hand, three isolates (E. faecium NW1, 2, and 3) showed more than $70 \%$ survival rates after exposure to $0.5 \%$ ox gall (Figure 2A). The $0.5 \%$ ox gall was selected for further studies, unless indicated otherwise.

\section{The Correlations Between the Gene Expression of Putative TCSs and Bile Salt Resistance}

To determine whether TCSs were involved in the resistance of E. faecium to bile salts, 8 TCSs were selected for measuring the expression of these genes in response to $0.5 \%$ ox gall. As shown in Figure 2B, there was a significantly positive correlation between the survival rate and the expressions of $R R 4(0.771, P=0.025)$ and $H K 4(0.804, P=0.016)$. The positive correlation between the survival rate and the expressions of $\operatorname{liaR}(0.686, P=0.060)$ and liaS $(0.689, P=0.059)$ tended to be significant. These results suggested that liaR, liaS, RR4, and HK4 genes may contribute to bile salt resistance in E. faecium. The correlations between the gene expression of the remaining putative or known TCSs and bile salt resistance were not significant.

\section{The Effect of liaR, liaS, bsrR, and bsrS Mutants on the Bile Salt Resistance in E. faecium NW2}

Considering the importance of $R R 4$ and $H K 4$ genes in bile salt resistance, these putative and previously unstudied genes were renamed as $b s r R$ and $b s r S$, for bile salt resistance response regulator and bile salt resistance sensor histidine kinase, respectively.

To confirm the involvement of liaR, liaS, bsrR, and $b s r S$ genes in resistance to bile salts, mutants of gene disruption were constructed using E. faecium NW2 due to its high bile resistant ability and up-regulation of liaR, liaS, $b s r R$, and $b s r S$ genes after exposure to ox gall. All mutants had similar growth curves as the parental strain NW2 in MRS broth in the absence of ox gall (data not shown). As showed in Figure 3, disruption of liaR, liaS, $b s r R$, and $b s r S$ significantly decreased the survival rate after exposure to $0.5,1$, and $2 \%$ ox gall compared to the E. faecium NW2 wild type. Complementation of the liaS gene resulted in restoration of survival in ox gall to levels of wild-type NW2 (Figure 3). However, the liaR, bsrR, and bsrS complemented strains were not obtained after several attempts. These results indicated that liaR, liaS, $b s r R$, and $b s r S$ were important for bile salt resistance in E. faecium.

\section{Characterization of the BsrXRS System in E. faecium}

In analysis of the genomic location of $b s r R$ and $b s r S$, it was found that the $5^{\prime}$-end of the $b s r R$ overlaps with 20 bases of the $3^{\prime}$-end of a 351-bp gene encoding a hypothetical protein (HMPREF0351_11749, renamed as $b s r X$ ) and the $5^{\prime}$-end of the $b s r S$ overlaps with a base of the $3^{\prime}$-end of $b s r R$, which suggest that $b s r X, b s r R$, and $b s r S$ may exist in an operon (Figure 4A). We validated that these 3 genes were co-transcribed, forming a single operon by RT-PCR (Figure 4B). 


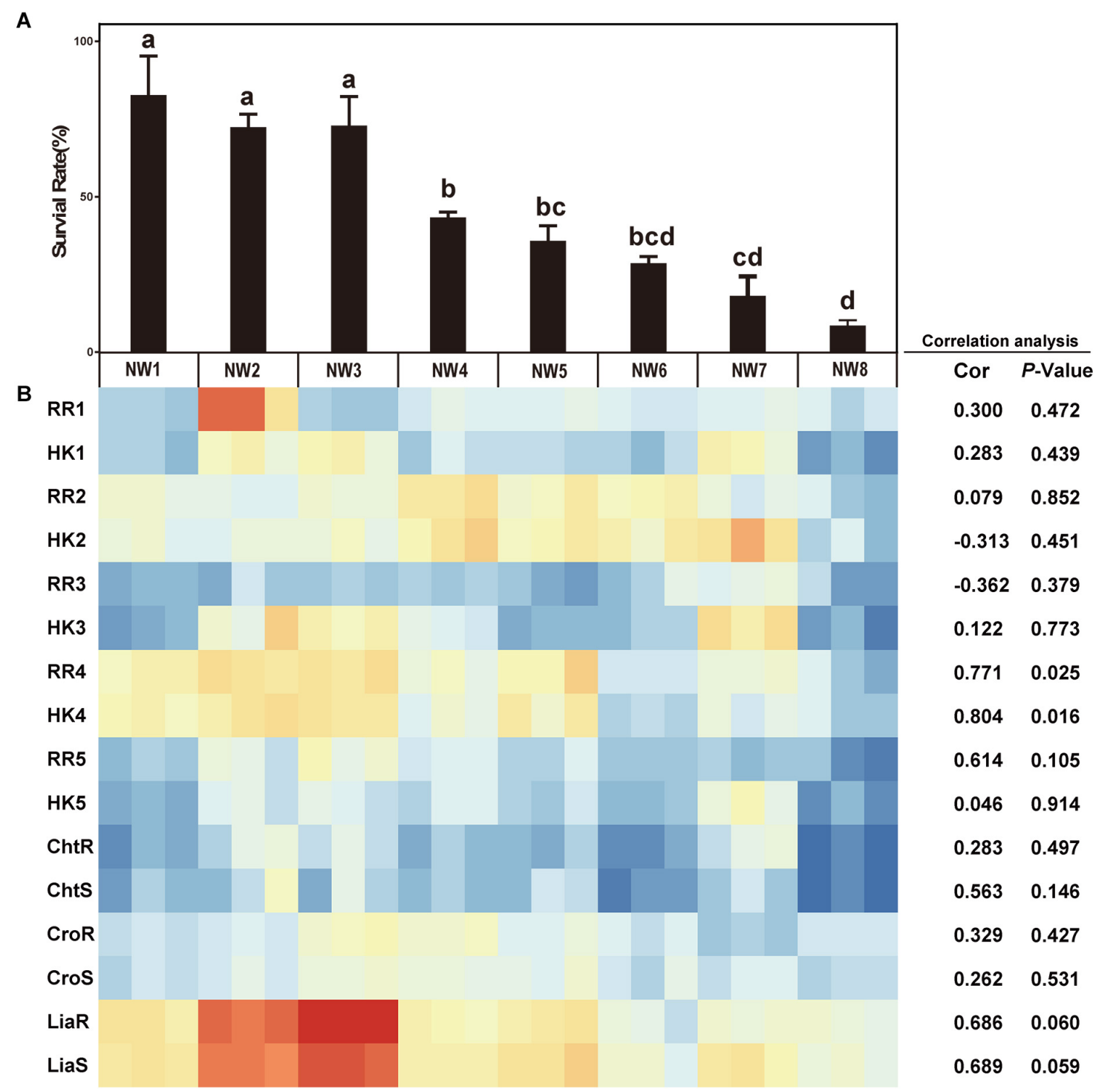

FIGURE 2 | The correlations between the gene expressions of TCSs and bile salt resistance. (A) Survival rates of E. faecium isolates after 30 min exposure to $0.5 \%$ ox gall. Data are shown as mean \pm SD from three independent biological replicates. Different letters above bars indicate the survival rates are significant differences among $E$. faecium isolates $(P<0.05)$. (B) The heatmap of expression of TCS genes after $0.5 \%$ ox gall addition compared with the time point preceding the bile addition (B, left panel). Red indicates up-regulated gene expression and blue denotes down-regulated gene expression. The color bar right indicates the expression scales [represented as $\log _{2}$ (fold change)]. Correlations between the survival rates in $0.5 \%$ ox gall and the expressions of TCS genes in E. faecium were performed using Pearson's product-moment correlation in $\mathrm{R}$ software. The Cor value represents the correlation coefficient and $P$-value $<0.05$ indicates that the correlation is significantly different.

The sequence analysis of BsrR revealed that the C-terminal of BsrR harbors a DNA-binding domain, suggesting that BsrR may function as a transcription regulator. To examine whether BsrR autoregulates directly, we performed EMSA with purified BsrR protein. The BsrR was showed to bind to a 143-bp intergenic region directly upstream of $b s r X$, thus suggesting BsrR to directly regulate the transcription of its own operon (Figure 4C).

To further determine whether BsrR in the Enterococcus genus can function as a transcription regulator, protein sequences of the BsrR from 7 strains including E. faecium DO were aligned. There were $86 \%$ identities and a conserved DNAbinding domain (Thr-164, Ser-183, Arg-184, Thr-202, Ala-205, Lys-213, Ile-214, Thr-224, and Gly-229) (Supplementary Figure S1), implying that these BsrR homologs might have a conserved DNA-binding site. By submitting the DNA sequences of upstream of the BsrXRS system from 7 bacterial species to the DMINDA 2.0 web server (Yang et al., 2017), a putative BsrR-binding site, the consensus sequence TMGAGTATAMTA, was found in the Enterococcus genus bacteria (Table 2). 

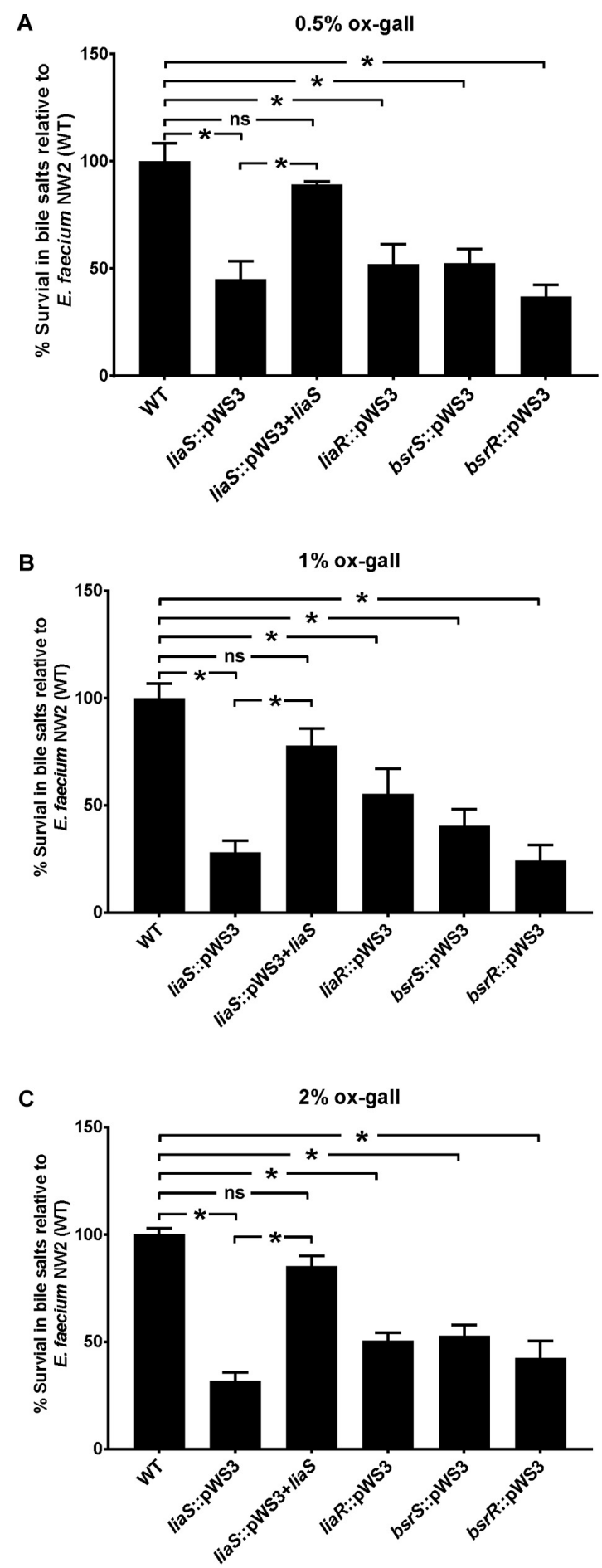

FIGURE 3 | The effect of mutation of liaR, liaS, bsrR, and bsrS genes on resistance to ox gall by $E$. faecium NW2. Survival rates of $E$. faecium NW2 wild type (WT) and its mutants with insertional mutagenesis of liaS (liaS:: pWS3), liaR (liaR::pWS3), bsrR (bsrR::pWS3), and bsrS (bsrS::pWS3) genes and the complementation strain of liaS (liaS:: pWS3 + liaS) after 30 min exposure to 0.5 (A), 1 (B), 2\% ox gall (C). Data are mean \pm SD of three independent experiments. Asterisk above bars indicate the survival rates are significant differences between WT and mutant strains or complementation strain $(P<0.05)$.

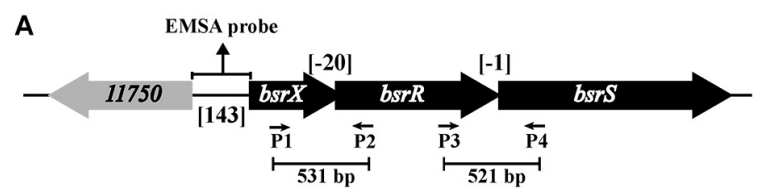

B

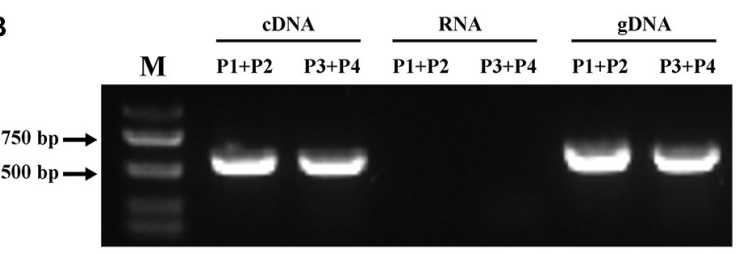

C
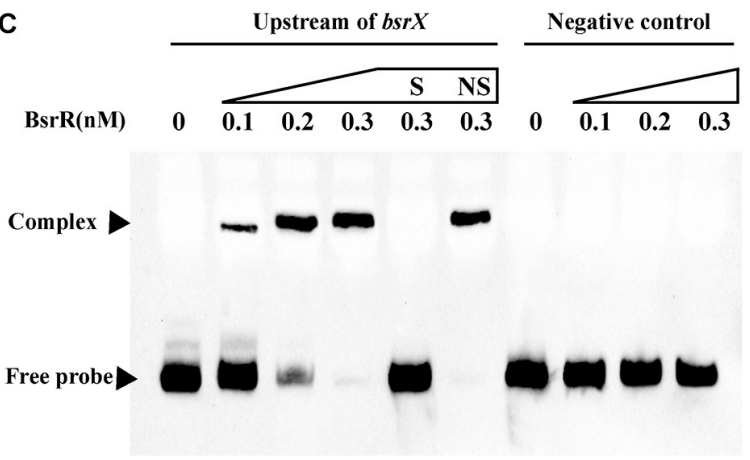

FIGURE 4 | Characterization of the BsrXRS system in E. faecium.

(A) Schematic representation of the BsrXRS system in E. faecium. (B) RT-PCR was performed for studying co-transcription using CDNA, RNA (negative control) and genomic DNA (positive control). Location of each intergenic primer pair for RT-PCR is shown in (A). (C) EMSA using biotin-labeled probes containing the intergenic region upstream of bsrX (143-bp) or negative control (150 bp) incubated with indicated amounts of BsrR protein. The negative control was amplified from the coding region of housekeeping gene ddlA, which does not share sequence identity with the intergenic region upstream of bsrX. EMSAs in the presence of 200-fold unlabeled specific probe (S, upstream of $b s r X$ ) or non-specific (NS, negative control) competitor DNA were performed as controls. Free DNA fragments and BsrR-DNA complexes are labeled.

\section{Characterization of the Potential Target Genes for the BsrXRS System}

To determine whether BsrR in the Enterococcus genus can also function as a transcription regulator for expression of other genes, an in silico genome-wide search was performed for putative BsrR target genes using the identified consensus sequence TMGAGTATAMTA as the BsrR-binding motif. As shown in Table 3, 27 putative target genes were identified.

Expression of 25 putative target genes was measured by RTqPCR, while expression of HMPREF035_10301 and 10302 was not measured due to lack of suitable specific primers. Among 25 tested genes, 16 genes were differentially expressed between the E. faecium NW2 wild-type and the $b s r R$ mutant after exposure to $0.5 \%$ ox gall (Figure 5). Three genes, $b s r X, b s r R$, and $b s r S$, exist in an operon bsrXRS as described above. HMPREF0351_12077 
TABLE 2 | Putative BsrR-binding sites in the promoter of the BsrXRS system.

\begin{tabular}{|c|c|c|c|c|}
\hline & & Distance $^{a}$ & (bp) & \\
\hline Strain & Site & $d_{\text {TLS }}$ & $d_{-10}$ & Locus Tag \\
\hline E. faecium DO & TAGAGTATACTA & -38 & -5 & HMPREF0351_11749 \\
\hline E. mundtii QU 25 & TAGAGTATACTA & -37 & -5 & EMQU_1779 \\
\hline E. hirae ATCC 9790 & TAGAGTATACTA & -37 & -5 & EHR_09675 \\
\hline E. faecalis V583 & TAGAGTATACTA & -54 & -5 & EF1260 \\
\hline E. gallinarum FDAARGOS_163 & TCGAGTATACTA & -33 & -5 & AL523_09775 \\
\hline E. casseliflavus EC20 & TCGAGTATACTA & -33 & -5 & ECBG_02917 \\
\hline E. silesiacus LMG 23085 & TAGAGTATAATA & -51 & -5 & ATZ33_03865 \\
\hline
\end{tabular}

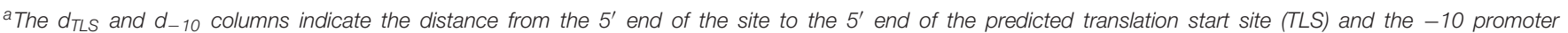
element, respectively.

is annotated as encoding a lipoate-protein ligase $\mathrm{A}(\mathrm{lplA})$. The lplA, 12078 and 12079 were co-transcribed and belong to a same operon (Figures 6A,B). As shown in Figure 6C, BsrR was able to bind the upstream of $l p l A$ gene, indicating that BsrR directly regulate the $l p l A$ operon. Seven genes are putatively involved in amino acid metabolism (HMPREF0351_11989 and 10965), fatty acid biosynthesis (HMPREF0351_11295), secondary metabolites biosynthesis (HMPREF0351_10954), inorganic ion transport and metabolism (HMPREF0351_10955), cell wall maintenance (HMPREF0351_10944), and DNA mismatch repair (HMPREF0351_11678). The other target genes encode hypothetical proteins of unknown functions (HMPREF0351_11172, 11173, 12076, and 12672).

\section{DISCUSSION}

Bile salts execute antimicrobial effects through disturbing cell membrane and macromolecule stability, and inducing oxidative stress, DNA damage and protein mis-folding in bacterial cells (Ruiz et al., 2013). Thus, the ability to adapt and respond to bile salts is essential for the survival and persistence of intestinal bacteria in gastrointestinal tracts. Two-component systems (TCSs) are dominant regulated mechanisms of bacteria in response to environmental stimuli (Groisman, 2016). Several studies have shown that TCSs are involved in resistance to bile salts in various bacterial species. However, the involvement of TCSs in E. faecium's resistance to bile salts has not been reported. As a successful colonizer in the gastrointestinal tract of various hosts including humans and animals, E. faecium must have evolved mechanisms to sense, respond to and resist bile salts. The results from the current study indicate that LiaFSR and BsrXRS contributed to bile salt resistance of E. faecium.

LiaFSR was shown to be involved in bile resistance in E. faecium isolates. The positive correlation between the survival rate in $0.5 \%$ ox gall and the expressions of liaSR genes tended to be significant. More importantly, disruption of liaR or liaS significantly reduced the survival rate of mutants in different concentrations of bile salts compared to the E. faecium wild type. Our results for the LiaFSR system in E. faecium were supported by a previous study in E. faecalis in which the liaR mutant had a low survival rate after exposure to bile (Harp et al., 2016).
The LiaFSR system was first identified in the response against lipid II interfering antibiotics (bacitracin, nisin, ramoplanin, and vancomycin) in Bacillus subtilis (Mascher et al., 2004). The role of LiaFSR in E. faecium and E. faecalis has mainly been described recently in the context of daptomycin resistance (Reyes et al., 2015). Given that cell membrane is a major attack target of bile salts, our finding expands the role of LiaFSR in dealing with cell membrane stress in E. faecium.

Cross-resistance against bile salts and antibiotics may exist. Saito et al. (2014) found the supplementing cultures with $0.2 \%$ bile significantly enhanced survival of E. faecalis OG1RF when exposed to daptomycin through incorporation of exogenous fatty acids and altering the fatty acid composition of cell membrane. In addition, LiaR-deficient strain of E. faecalis can incorporate exogenous fatty acids into its membrane, then increase the survival rate when exposed to a variety of membrane damage agents, such bile, SDS and daptomycin (Harp et al., 2016).

The functions of BsrXRS have not been explored before. In this study, expression of $b s r R$ and $b s r S$ was significantly correlated with the survival rate of E. faecium in $0.5 \%$ ox gall. There were 4 amino acid polymorphisms (F for NW1, 2, 3, 5, and 6 and V for NW4, 7, and 8 at position 176; K for NW2, 3, 4, 7, and 8 and R for NW 1, 5, and 6 at position 243; A for NW1, 2, 3, 5, and 6 and $\mathrm{T}$ for NW4, 7, and 8 at position 471; K for NW1, 2, 3, 5, and 6 and $\mathrm{E}$ for NW4, 7, and 8 at position 481) in the BsrS protein, while no difference was found in the BsrR protein. The amino acid at position 176 is located in a predicted trans-membrane domain in the sensor histidine kinase BsrS, which is essential for signal transmission from extracellular to cytoplasm (Zschiedrich et al., 2016). The other two amino acid substitutions at positions 471 and 481 are located in C-terminal ATP-binding catalytic domain, which is responsible for autophosphorylation of $\mathrm{HK}$. These amino acid substitutions may affect the signal transduction and activation of BsrR and change the transcription of target genes, resulting in different bile salt resistance in E. faecium strains. The sequence analysis of BsrX using revealed that BsrX harbors 3 transmembrane helices, suggesting BsrX may be a small membrane protein (116 aa). Despite repeated attempts, we were unable to obtain a mutant strain of $b s r X$ gene. Therefore, the function of $b s r X$ gene was not validated in the present study.

Twenty-seven potential target genes for BsrR were revealed and these target genes are involved in multiple cellular functions. 
TABLE 3 | Putative target genes of BsrR in genome of E. faecium DO.

\begin{tabular}{|c|c|c|c|}
\hline Operon & Locus Tag & Product & $\begin{array}{c}\text { COG } \\
\text { functional } \\
\text { categories }^{a}\end{array}$ \\
\hline \multirow[t]{3}{*}{1107280} & HMPREF0351_11747 & Sensor histidine kinase & $\mathrm{T}$ \\
\hline & HMPREF0351_11748 & Response regulator & $\mathrm{T}$ \\
\hline & HMPREF0351_11749 & Hypothetical protein & S \\
\hline 3824662 & HMPREF0351_11750 & HAD superfamily hydrolase & $S$ \\
\hline 3824769 & HMPREF0351_12076 & Hypothetical protein & S \\
\hline \multirow[t]{3}{*}{1107358} & HMPREF0351_12077 & Lipoate-protein ligase A & $\mathrm{H}$ \\
\hline & HMPREF0351_12078 & $\begin{array}{l}\text { HD family metal-dependent } \\
\text { phosphohydrolase }\end{array}$ & S \\
\hline & HMPREF0351_12079 & HAD superfamily hydrolase & S \\
\hline 3824741 & HMPREF0351_11989 & $\begin{array}{l}\text { Thioredoxin-disulfide } \\
\text { reductase }\end{array}$ & $\mathrm{O}$ \\
\hline 3824782 & HMPREF0351_12122 & $\begin{array}{l}\text { GNAT family } \\
\text { acetyltransferase }\end{array}$ & K \\
\hline 3824379 & HMPREF0351_10965 & $\begin{array}{l}\text { 2-hydroxy-3-oxopropionate } \\
\text { reductase }\end{array}$ & 1 \\
\hline 3824637 & HMPREF0351_11678 & $\begin{array}{l}\text { DNA-directed DNA } \\
\text { polymerase III subunit alpha }\end{array}$ & $\mathrm{L}$ \\
\hline \multirow[t]{2}{*}{1106980} & HMPREF0351_10295 & $\begin{array}{l}\text { 2-dehydropantoate } \\
\text { 2-reductase }\end{array}$ & $\mathrm{H}$ \\
\hline & HMPREF0351_10296 & Regulatory protein & S \\
\hline \multirow[t]{2}{*}{1106982} & HMPREF0351_10301 & Acetyltransferase & K \\
\hline & HMPREF0351_10302 & Hypothetical protein & K \\
\hline 3824725 & HMPREF0351_11918 & N-acetyltransferase GCN5 & K \\
\hline 3824372 & HMPREF0351_10954 & $\begin{array}{l}\text { GNAT family } \\
\text { acetyltransferase }\end{array}$ & Q \\
\hline 3824373 & HMPREF0351_10955 & Permease & $\mathrm{P}$ \\
\hline 3824469 & HMPREF0351_11172 & $\begin{array}{l}\text { Fosfomycin resistance } \\
\text { protein FosX }\end{array}$ & S \\
\hline 3824470 & HMPREF0351_11173 & Hypothetical protein & $S$ \\
\hline 3824507 & HMPREF0351_11295 & $\begin{array}{l}\text { Enoyl- acyl-carrier-protein } \\
\text { reductase NADH }\end{array}$ & 1 \\
\hline 3824508 & HMPREF0351_11296 & $\begin{array}{l}\text { 3-hydroxydecanoyl-ACP } \\
\text { dehydratase }\end{array}$ & 1 \\
\hline 3824962 & HMPREF0351_12672 & Hypothetical protein & S \\
\hline 3824963 & HMPREF0351_12673 & $\begin{array}{l}\text { Collagen-binding } \\
\text { MSCRAMM Scm (Fms10) }\end{array}$ & S \\
\hline 3824527 & HMPREF0351_11330 & Glycine C-acetyltransferase & $\mathrm{H}$ \\
\hline 3824364 & HMPREF0351_10944 & $\begin{array}{l}\text { Teichoic acid glycosylation } \\
\text { protein GtrA }\end{array}$ & S \\
\hline
\end{tabular}

aThe one-letter codes represent the following COG functional categories: $H$, coenzyme transport and metabolism; I, lipid transport and metabolism; $K$, transcription; $L$, replication, recombination and repair; $O$, posttranslational modification, protein turnover; chaperones; $P$, inorganic ion transport and metabolism; Q, secondary metabolites biosynthesis, transport and catabolism; $S$, function unknown; T, signal transduction mechanisms.

Sixteen genes were found as differentially expressed between E. faecium NW2 wild-type and $b s r R$ mutant after exposure to $0.5 \%$ ox gall. Of the 16 differentially expressed genes, 7 genes (bsrX, bsrR, bsrS, lplA, HMPREF0351_10944, 11173, 12672) were upregulated after exposure to $0.5 \%$ ox gall. Our result was supported by a previous study in E. faecium E1162 in which these 7 genes were also upregulated after addition of bile salts to the culture medium (Zhang et al., 2013). However, none of the 7 genes showed significant differential expression in E. faecalis
V583 in the presence of ox gall (Solheim et al., 2007). On the other hand, a TCS CroRS system was induced in E. faecalis V583 after exposure to ox gall (Solheim et al., 2007). However, expression of the CroRS system was not significant in E. faecium NW2 in our study and also in E. faecium E1162 (Zhang et al., 2013). Although E. faecium is a close relative of $E$. faecalis, these findings imply that different mechanisms are involved in bile resistance in $E$. faecium and E. faecalis.

Among these 16 differentially expressed target genes of BsrR, 3 genes ( $b s r X, b s r R$, and $b s r S)$ constitute an operon bsrXRS as discussed above. Another operon targeted by BsrR consists of 3 genes, lplA encoding a lipoate-protein ligase A (HMPREF0351_12077), a gene encoding HD family metaldependent phosphohydrolase (HMPREF0351_12078) and a gene encoding HAD superfamily hydrolase (HMPREF0351_12079). Whether involvement of the HD family metal-dependent phosphohydrolase and HAD superfamily hydrolase in bile resistance is unknown, lplA gene may play an important role in bile salt resistance. This was supported by the observation that mutation of $l p l A$ induced a $2-\log$ reduction of viability in comparison with the wild type L. monocytogenes after $8 \mathrm{~h}$ exposure to porcine gallbladder bile (Dowd et al., 2011). LplA catalyzes the formation of lipoyl-AMP from lipoate and ATP and transfers the lipoyl moiety to a specific lysine residue on the acyltransferase subunit of $\alpha$-ketoacid dehydrogenase complexes. In particular, the branched-chainketoacid dehydrogenase (BCDH) participates in the degradation of branched chain amino acids to generate branched-chain CoA (BC-CoA) molecules. In many Gram-positive bacteria, these short $\mathrm{BC}-\mathrm{CoA}$ molecules are used chiefly as primers for generating longer branched-chain fatty acids that can modulate membrane fluidity. This change of membrane fluidity may promote E. faecium to resist bile salts toxicity. However, further study is required to corroborate this hypothesis.

Bacterial cell membrane and cell wall are main targets of bile salts. Thus changes in their composition appear to be the most prevalent actions to resist bile salt in bacteria (Ruiz et al., 2013). Studies have shown that resistance to bile salt in E. faecalis involved changes in fatty acid biosynthesis (Solheim et al., 2007) and in membrane composition or cell wall synthesis (Rincé et al., 2003). In addition, DNA mismatch repair proteins repair the DNA damage caused by bile salts and are important for bacterial bile resistance (Rincé et al., 2003). In this study, the target genes of BsrR from functional annotation are involved in amino acid metabolism (HMPREF0351_11989 and 10965), fatty acid biosynthesis (HMPREF0351_11295), secondary metabolites biosynthesis (HMPREF0351_10954), inorganic ion transport and metabolism (HMPREF0351_10955), cell wall maintenance (HMPREF0351_10944), and DNA mismatch repair (HMPREF0351_11678). These target genes may contribute to bile salt resistance in E. faecium.

The Enterococcus genus is an ancient genus of microbes that are highly adapted to living in complex environments and surviving harsh conditions. The BsrXRS system is highly conserved in Enterococcus genus, indicating that BsrXRS may play a prominent role in responding to environmental changes among bacteria in the Enterococcus genus. 

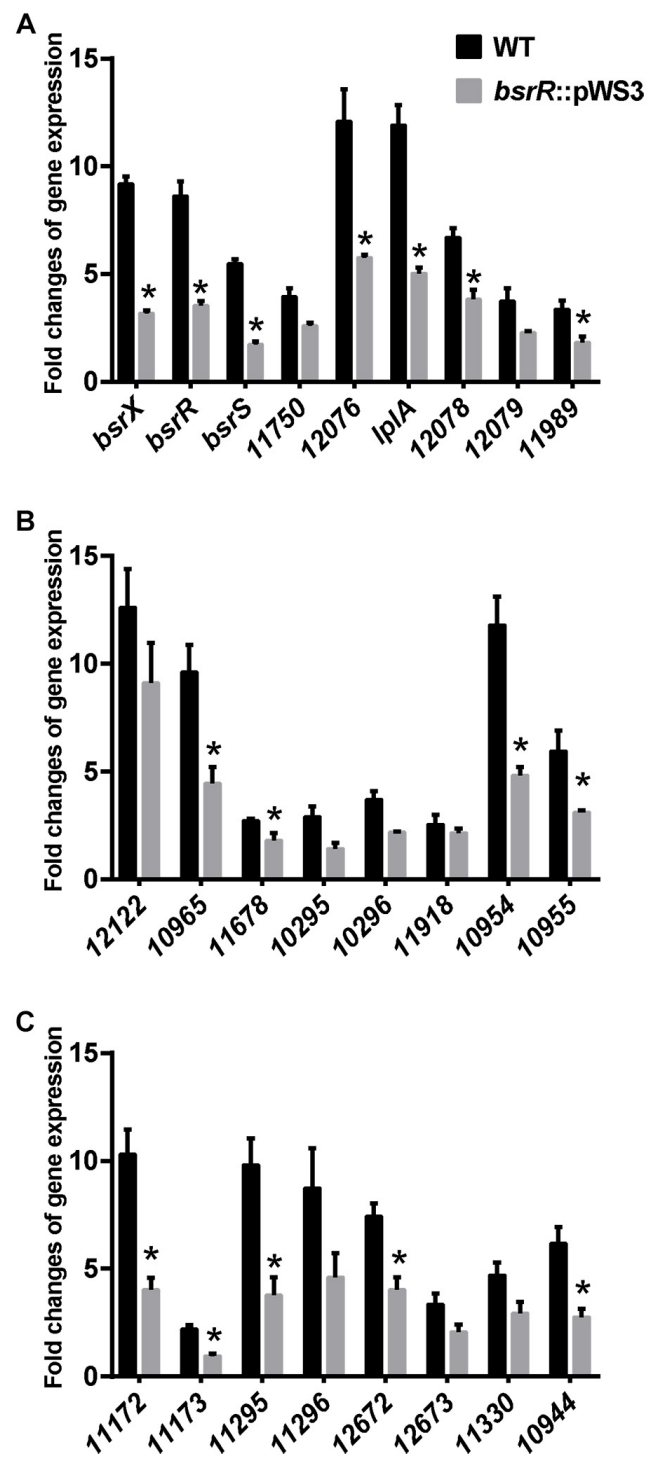

FIGURE 5 | The expression of target genes of BsrR in response to bile salts. (A-C) Relative expression of target genes of BsrR in response to $0.5 \%$ ox-gall was determined by RT-qPCR. Fold changes of gene expression of wild-type (WT) and the bsrR mutant (bsrR::pWS3) of E. faecium NW2 after exposure to $0.5 \%$ ox-gall for $30 \mathrm{~min}$, were calculated relative to WT and bsrR::pWS3 strains before the bile salts addition, respectively. Data are shown as mean \pm SD from three independent biological replicates. Asterisk above bars indicate significant difference between WT and the bsrR mutant $(P<0.05)$. The target genes, bsrX (HMPREF0351_11749), bsrR (HMPREF0351_11748), bsrS (HMPREF0351_11747), 11750 (HMPREF0351_11750), 12076 (HMPREF0351_12076), IPIA (HMPREF0351_12077), 12078 (HMPREF0351_12078), 12079 (HMPREF0351_12079), 11989 (HMPREF0351_11989), 12122 (HMPREF0351_12122), 10965 (HMPREF0351_10965), 11678 (HMPREF0351_11678), 10295 (HMPREF0351_10295), 10296 (HMPREF0351_10296), 11918 (HMPREF0351_11918), 10954 (HMPREF0351_10954), 10955 (HMPREF0351_10955), 11172 (HMPREF0351_11172), 11173 (HMPREF0351_11173), 11295 (HMPREF0351_11295), 11296 (HMPREF0351_11296), 12672 (HMPREF0351_12672), 12673 (HMPREF0351_12673), 11330 (HMPREF0351_11330), 10944 (HMPREF0351_10944), were predicted with putative BsrR-binding motif in genome of $E$. faecium DO.

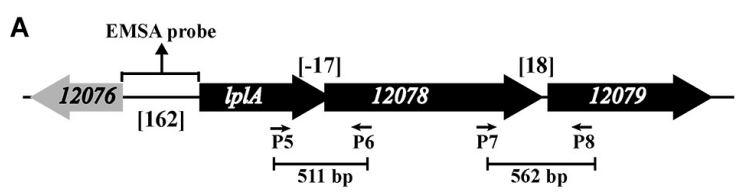

B

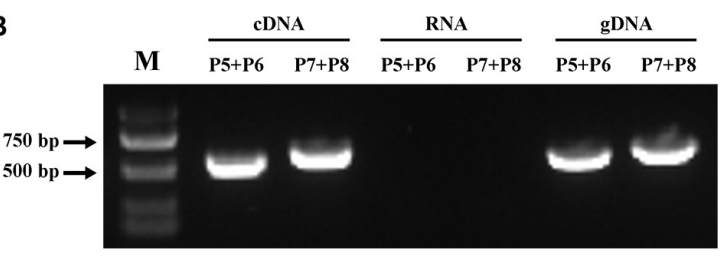

C

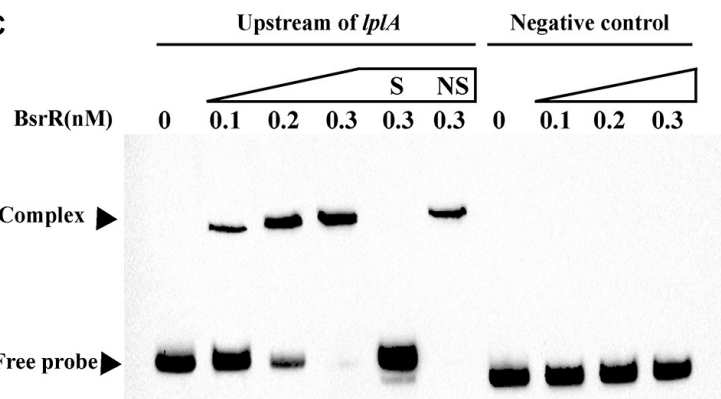

FIGURE 6 | Characterization of the Ip/A operon that regulated by BsrR. (A) Schematic representation of IplA operon in E. faecium. (B) RT-PCR was performed for studying co-transcription using cDNA, RNA (negative control) and genomic DNA (positive control). Location of each intergenic primer pair for RT-PCR is shown in (A). (C) EMSA using biotin-labeled probes containing the intergenic region upstream of Ip/A (162-bp) or negative control (150 bp) incubated with indicated amounts of BsrR protein. The negative control was amplified from the coding region of housekeeping gene $d d l A$, which does not share sequence identity with the intergenic region upstream of bsrX. EMSAs in the presence of 200 -fold unlabeled specific probe (S, upstream of $/ p / A)$ or non-specific (NS, negative control) competitor DNA were performed as controls. Free DNA fragments and BsrR-DNA complexes are labeled.

\section{CONCLUSION}

In summary, our data demonstrate that E. faecium can improve the resistance to bile salts by up-regulating LiaFSR and BsrXRS systems. The BsrXRS system up-regulates gene expression of target genes that involving in change of membrane fluidity, fatty acid biosynthesis, cell wall maintenance, DNA mismatch repair. These findings provide potential molecular mechanisms for resistance to bile salts by E. faecium.

\section{AUTHOR CONTRIBUTIONS}

LZ and XZ contributed to the design of the experiments and prepared the manuscript of this publication. LZ, LW, PT, and TB performed the experiments. LZ and LL analyzed the data. All authors read and approved the final manuscript. 


\section{FUNDING}

This work was supported by funding from National Natural Science Foundation of China (31672445) and a University Scientific Research Fund project (Z109021718).

\section{ACKNOWLEDGMENTS}

We are grateful to Axel Hartke (University of Caen, France), Willem van Schaik (University of Birmingham,

\section{REFERENCES}

Adediran, J., Leatham-Jensen, M. P., Mokszycki, M. E., Frimodt-Moller, J., Krogfelt, K. A., Kazmierczak, K., et al. (2014). An Escherichia coli Nissle 1917 missense mutant colonizes the streptomycin-treated mouse intestine better than the wild type but is not a better probiotic. Infect. Immun. 82, 670-682. doi: 10.1128/IAI.01149-13

Brückner, R., Wagner, E., and Götz, F. (1993). Characterization of a sucrase gene from Staphylococcus xylosus. J. Bacteriol. 175, 851-857. doi: 10.1128/jb.175.3. 851-857.1993

Capra, E. J., and Laub, M. T. (2012). Evolution of two-component signal transduction systems. Annu. Rev. Microbiol. 66, 325-347. doi: 10.1146/ annurev-micro-092611-150039

Dowd, G. C., Joyce, S. A., Hill, C., and Gahan, C. G. (2011). Investigation of the mechanisms by which Listeria monocytogenes grows in porcine gallbladder bile. Infect. Immun. 79, 369-379. doi: 10.1128/IAI.00330-10

Favaro, L., Basaglia, M., Casella, S., Hue, I., Dousset, X., Gombossy de Melo Franco, B. D., et al. (2014). Bacteriocinogenic potential and safety evaluation of non-starter Enterococcus faecium strains isolated from home made white brine cheese. Food Microbiol. 38, 228-239. doi: 10.1016/j.fm.2013.09.008

Feng, J., Wang, L., Zhou, L., Yang, X., and Zhao, X. (2016). Using in vitro immunomodulatory properties of lactic acid bacteria for selection of probiotics against Salmonella infection in broiler chicks. PLoS One 11:e0147630. doi: 10. 1371/journal.pone.0147630

Groisman, E. A. (2016). Feedback control of two-component regulatory systems. Annu. Rev. Microbiol. 70, 103-124. doi: 10.1146/annurev-micro-102215095331

Guzman Prieto, A. M., Wijngaarden, J., Braat, J. C., Rogers, M. R. C., Majoor, E., Brouwer, E. C., et al. (2017). The two-component system ChtRS contributes to chlorhexidine tolerance in Enterococcus faecium. Antimicrob. Agents Chemother. 61:e2122-16. doi: 10.1128/AAC.02122-16

Harp, J. R., Saito, H. E., Bourdon, A. K., Reyes, J., Arias, C. A., Campagna, S. R., et al. (2016). Exogenous fatty acids protect Enterococcus faecalis from daptomycininduced membrane stress independently of the response regulator LiaR. Appl. Environ. Microbiol. 82, 4410-4420. doi: 10.1128/AEM.00933-16

Hong, H. J., Hutchings, M. I., and Buttner, M. J. (2008). "Vancomycin resistance VanS/VanR two-component systems," in Bacterial Signal Transduction: Networks and drug Targets. Advances in Experimental Medicine and Biology, Vol. 631, ed. R. Utsumi (New York, NY: Springer), 200-213. doi: 10.1007/9780-387-78885-2_14

Kellogg, S. L., Little, J. L., Hoff, J. S., and Kristich, C. J. (2017). Requirement of the CroRS two-component system for resistance to cell wall-targeting antimicrobials in Enterococcus faecium. Antimicrob. Agents Chemother. 61:e02461-16. doi: 10.1128/AAC.02461-16

Koskenniemi, K., Laakso, K., Koponen, J., Kankainen, M., Greco, D., Auvinen, P., et al. (2011). Proteomics and transcriptomics characterization of bile stress response in probiotic Lactobacillus rhamnosus GG. Mol. Cell Proteomics 10:M110.002741. doi: 10.1074/mcp.M110.002741

Kus, J. V., Gebremedhin, A., Dang, V., Tran, S. L., Serbanescu, A., and Barnett Foster, D. (2011). Bile salts induce resistance to polymyxin in enterohemorrhagic Escherichia coli O157:H7. J. Bacteriol. 193, 4509-4515. doi: 10.1128/JB.00200-11
United Kingdom), and Reinhold Brückner (University of Kaiserslautern, Germany) for generously providing the E. coli EC1000 strain and plasmid pWS3 and pRB473.

\section{SUPPLEMENTARY MATERIAL}

The Supplementary Material for this article can be found online at: https://www.frontiersin.org/articles/10.3389/fmicb. 2019.01048/full\#supplementary-material

Le Breton, Y., Boel, G., Benachour, A., Prevost, H., Auffray, Y., and Rince, A. (2003). Molecular characterization of Enterococcus faecalis two-component signal transduction pathways related to environmental stresses. Environ. Microbiol. 5, 329-337. doi: 10.1046/j.1462-2920.2003.00405.x

Lebreton, F., van Schaik, W., McGuire, A. M., Godfrey, P. Griggs, A., Mazumdar, V., et al. (2013). Emergence of epidemic multidrug-resistant Enterococcus faecium from animal and commensal strains. mBio 4:e00534-13. doi: 10.1128/mBio 00534-13

Leenhouts, K. (1996). A general system for generating unlabelled gene replacements in bacterial chromosomes. Mol. Gen. Genet. 253, 217-224. doi: $10.1007 / \mathrm{s} 004380050315$

Leverrier, P., Dimova, D., Pichereau, V., Auffray, Y., Boyaval, P., and Jan, G. (2003). Susceptibility and adaptive response to bile salts in Propionibacterium freudenreichii: physiological and proteomic analysis. Appl. Environ. Microbiol. 69, 3809-3818. doi: 10.1128/aem.69.7.3809-3818.2003

Mao, X., Ma, Q., Zhou, C., Chen, X., Zhang, H., Yang, J., et al. (2014). DOOR 2.0: presenting operons and their functions through dynamic and integrated views. Nucleic Acids Res. 42, D654-D659. doi: 10.1093/nar/gkt1048

Mascher, T., Zimmer, S. L., Smith, T. A., and Helmann, J. D. (2004). Antibioticinducible promoter regulated by the cell envelope stress-sensing twocomponent system LiaRS of Bacillus subtilis. Antimicrob. Agents Chemother. 48, 2888-2896. doi: 10.1128/AAC.48.8.2888-2896.2004

Mendiburu, F. D. (2017). Agricolae: Statistical Procedures for Agricultural Research (Version 1.2-8). Available at: https://CRAN.R-project.org/package=agricolae (accessed September 12, 2017).

Ortet, P., Whitworth, D. E., Santaella, C., Achouak, W., and Barakat, M. (2015). P2CS: updates of the prokaryotic two-component systems database. Nucleic Acids Res. 43, D536-D541. doi: 10.1093/nar/gku968

Panesso, D., Reyes, J., Gaston, E. P., Deal, M., Londono, A., Nigo, M., et al. (2015). Deletion of liaR reverses daptomycin resistance in Enterococcus faecium independent of the genetic background. Antimicrob. Agents Chemother. 59, 7327-7334. doi: 10.1128/AAC.01073-15

Pfeiler, E. A., Azcarate-Peril, M. A., and Klaenhammer, T. R. (2007). Characterization of a novel bile-inducible operon encoding a two-component regulatory system in Lactobacillus acidophilus. J. Bacteriol. 189, 4624-4634. doi: 10.1128/JB.00337-07

Pingitore, E. V., Todorov, S. D., Sesma, F., and Franco, B. D. (2012). Application of bacteriocinogenic Enterococcus mundtii CRL35 and Enterococcus faecium ST88Ch in the control of Listeria monocytogenes in fresh Minas cheese. Food Microbiol. 32, 38-47. doi: 10.1016/j.fm.2012.04.005

R Core Team (2017). R: A Language and Environment for Statistical Computing (Version 3.4.3). Available at: https://www.R-project.org (accessed November 30, 2017).

Raphael, B. H., Pereira, S., Flom, G. A., Zhang, Q., Ketley, J. M., and Konkel, M. E. (2005). The Campylobacter jejuni response regulator, CbrR, modulates sodium deoxycholate resistance and chicken colonization. J. Bacteriol. 187, 3662-3670. doi: 10.1128/JB.187.11.3662-3670.2005

Reyes, J., Panesso, D., Tran, T. T., Mishra, N. N., Cruz, M. R., Munita, J. M., et al. (2015). A liaR deletion restores susceptibility to daptomycin and antimicrobial peptides in multidrug-resistant Enterococcus faecalis. J. Infect. Dis. 211, 1317 1325. doi: 10.1093/infdis/jiu602 
Rincé, A., Le Breton, Y., Verneuil, N., Giard, J.-C., Hartke, A., and Auffray, Y. (2003). Physiological and molecular aspects of bile salt response in Enterococcus faecalis. Int. J. Food Microbiol. 88, 207-213. doi: 10.1016/s0168-1605(03) 00182-x

Ruiz, L., Margolles, A., and Sanchez, B. (2013). Bile resistance mechanisms in Lactobacillus and Bifidobacterium. Front. Microbiol. 4:396. doi: 10.3389/fmicb. 2013.00396

Saito, H. E., Harp, J. R., and Fozo, E. M. (2014). Incorporation of exogenous fatty acids protects Enterococcus faecalis from membrane-damaging agents. Appl. Environ. Microbiol. 80, 6527-6538. doi: 10.1128/AEM.02044-14

Sanchez, B., Champomier-Verges, M. C., Anglade, P., Baraige, F., de Los ReyesGavilan, C. G., Margolles, A., et al. (2005). Proteomic analysis of global changes in protein expression during bile salt exposure of Bifidobacterium longum NCIMB 8809. J. Bacteriol. 187, 5799-5808. doi: 10.1128/JB.187.16.5799-5808. 2005

Solheim, M., Aakra, A., Vebo, H., Snipen, L., and Nes, I. F. (2007). Transcriptional responses of Enterococcus faecalis V583 to bovine bile and sodium dodecyl sulfate. Appl. Environ. Microbiol. 73, 5767-5774. doi: 10.1128/AEM.00651-07

Srinivasan, V. B., Vaidyanathan, V., Mondal, A., and Rajamohan, G. (2012). Role of the two component signal transduction system CpxAR in conferring cefepime and chloramphenicol resistance in Klebsiella pneumoniae NTUH-K2044. PLoS One 7:e33777. doi: 10.1371/journal.pone.0033777

Thompson, J. D., Higgins, D. G., and Gibson, T. J. (1994). CLUSTAL W: improving the sensitivity of progressive multiple sequence alignment through sequence weighting, position-specific gap penalties and weight matrix choice. Nucleic Acids Res. 22, 4673-4680. doi: 10.1093/nar/22.22.4673

Tran, T. T., Miller, W. R., Shamoo, Y., and Arias, C. A. (2016). Targeting cell membrane adaptation as a novel antimicrobial strategy. Curr. Opin. Microbiol. 33, 91-96. doi: 10.1016/j.mib.2016. 07.002

Veljovic, K., Popovic, N., Miljkovic, M., Tolinacki, M., Terzic-Vidojevic, A., and Kojic, M. (2017). Novel aggregation promoting factor AggE contributes to the probiotic properties of Enterococcus faecium BGGO9-28. Front. Microbiol. 8:1843. doi: 10.3389/fmicb.2017.01843
Whiteside, M. D., Winsor, G. L., Laird, M. R., and Brinkman, F. S. (2013). OrtholugeDB: a bacterial and archaeal orthology resource for improved comparative genomic analysis. Nucleic Acids Res. 41, D366-D376. doi: 10.1093/ nar/gks1241

Yang, J., Chen, X., McDermaid, A., and Ma, Q. (2017). DMINDA 2.0: integrated and systematic views of regulatory DNA motif identification and analyses. Bioinformatics 33, 2586-2588. doi: 10.1093/bioinformatics/ btx223

Zhang, X., Bierschenk, D., Top, J., Anastasiou, I., Bonten, M. J., Willems, R. J., et al. (2013). Functional genomic analysis of bile salt resistance in Enterococcus faecium. BMC Genomics 14:299. doi: 10.1186/1471-216414-299

Zhang, X., Paganelli, F. L., Bierschenk, D., Kuipers, A., Bonten, M. J., Willems, R. J., et al. (2012). Genome-wide identification of ampicillin resistance determinants in Enterococcus faecium. PLoS Genet. 8:e1002804. doi: 10.1371/journal.pgen. 1002804

Zhang, X., Vrijenhoek, J. E., Bonten, M. J., Willems, R. J., and van Schaik, W. (2011). A genetic element present on megaplasmids allows Enterococcus faecium to use raffinose as carbon source. Environ. Microbiol. 13, 518-528. doi: 10.1111/j.1462-2920.2010.02355.x

Zschiedrich, C. P., Keidel, V., and Szurmant, H. (2016). Molecular mechanisms of two-component signal transduction. J. Mol. Biol. 428, 3752-3775. doi: 10.1016/ j.jmb.2016.08.003

Conflict of Interest Statement: The authors declare that the research was conducted in the absence of any commercial or financial relationships that could be construed as a potential conflict of interest.

Copyright (c) 2019 Zhou, Wang, Tian, Bao, Li and Zhao. This is an open-access article distributed under the terms of the Creative Commons Attribution License (CC BY). The use, distribution or reproduction in other forums is permitted, provided the original author(s) and the copyright owner(s) are credited and that the original publication in this journal is cited, in accordance with accepted academic practice. No use, distribution or reproduction is permitted which does not comply with these terms. 